\title{
Swiss Science Concentrates
}

A CHIMIIA Column

(20)

\section{YAIC: A Bonding Chameleon with Heteropolyacetylene Features}

M. R. Kotyrba*, E. Cuervo-Reyes*, and R. Nesper*, Angew. Chem. Int. Ed. 2015, 54, 9606. ETH Zürich and EMPA Dübendorf Silicon carbide and aluminium carbide are extremely stable refractory compounds demonstrating the strength of the $\mathrm{Si}-\mathrm{C}$ and the Al-C bonds, respectively. Kotyrba, Cuervo-Reyes and Nesper describe a novel ternary aluminide-carbide, YAlC, which was prepared by a flux method. It crystallizes as a partially filledup TII structure, showing remarkable structural aspects at the border between Zintl phases and intermetallics. The compound represents a fascinating compromise between the polarized metal (stuffed intermetallic) and the semicovalent $\mathrm{Y}^{3+}[\mathrm{AlC}]^{3-}$ model. A key feature is the coexistence of two-centre and multi-center bonds. The latter appear as tapes meandering wherever there would be a direct $\mathrm{Al}-\mathrm{Al}$ or $\mathrm{Y}-\mathrm{Al}$ contact, and contain the residual electron density after the formation of the Al-C semi-covalent chains.
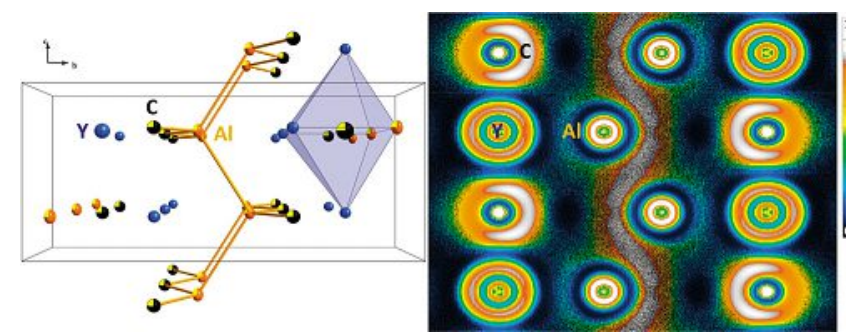

Structure and Mechanism of an Active Lipid-linked Oligosaccharide Flippase

C. Perez, S. Gerber, J. Boilevin, M. Bucher, T. Darbre, M. Aebi, J.-L. Reymond, and K. P. Locher*, Nature, 2015, 524, 433. ETH Zürich

The flipping of membrane-embedded lipids containing large, polar head groups is slow and energetically unfavourable, and is therefore catalysed by flippases, the mechanisms of which are unknown. A prominent example of a flipping reaction is the translocation of lipid-linked oligosaccharides that serve as donors

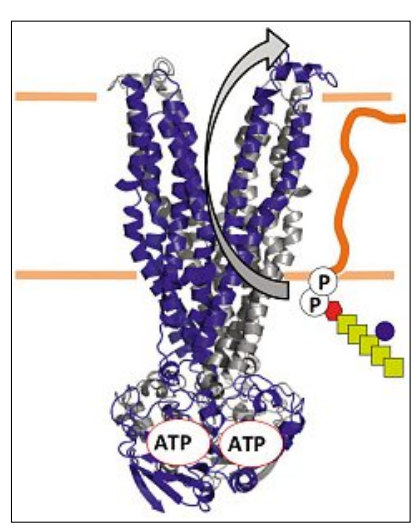
in $\mathrm{N}$-linked protein glycosylation. In Campylobacter jejuni, this process is catalysed by the $\mathrm{ABC}$ transporter PglK. Locher and coauthors present a mechanism of PglK-catalysed, lipid-linked oligosaccharide flipping based on crystal structure in distinct states, a newly devised in vitro flipping assay, and in vivo studies. The proposed mechanism is distinct from the classical alternatingaccess model observed in other transporters.

\section{3d-4f $\left\{\mathrm{Co}_{3}{ }_{3} \mathrm{Ln}(\mathrm{OR})_{4}\right\}$ Cubanes as Bio-Inspired Water Oxidation Catalysts}

F. Evangelisti, R. Moré, F. Hodel, S. Luber*, and G. R. Patzke*, J. Am. Chem. Soc. 2015, 137, 11076. University of Zürich

The $\left\{\mathrm{CaMn}_{4} \mathrm{O}_{5}\right\}$ oxygen evolving complex of photosystem II represents a major paradigm for the development of water oxidation catalysts (WOCs). However, translating its key features into active molecular WOCs remains a major challenge.

Patzke, Luber and co-workers now introduce $\left[\mathrm{Co}_{3}{ }_{3} \mathrm{Ln}(\mathrm{hmp})_{4}(\mathrm{OAc})_{5} \mathrm{H}_{2} \mathrm{O}\right]\left(\left\{\mathrm{Co}_{3}{ }_{3} \mathrm{Ln}(\mathrm{OR})_{4}\right\} ; \mathrm{Ln}=\mathrm{Ho}-\mathrm{Yb}, \mathrm{hmp}=\right.$ 2-(hydroxymethyl)pyridine) cubanes as new functional and stable model systems to explore a range of crucial design parameters, including core nuclearity, redox-inactive promoters, and ligand exchange properties. The highly active $\left\{\mathrm{Co}_{3}{ }_{3} \mathrm{Ln}(\mathrm{OR})_{4}\right\}$ cubanes advance promote bio-inspired design through the combination of $\mathrm{Ln}^{3+}$ core cations as redox-inactive $\mathrm{Ca}^{2+}$ analogues of nature's oxygen evolving complex with flexible aqua-/ acetate ligands. The $\mathrm{Ln}^{3+}$-enhanced ligand exchange of the $\left\{\mathrm{Co}_{3}^{\mathrm{II}} \mathrm{Ln}(\mathrm{OR})_{4}\right\}$ WOCs

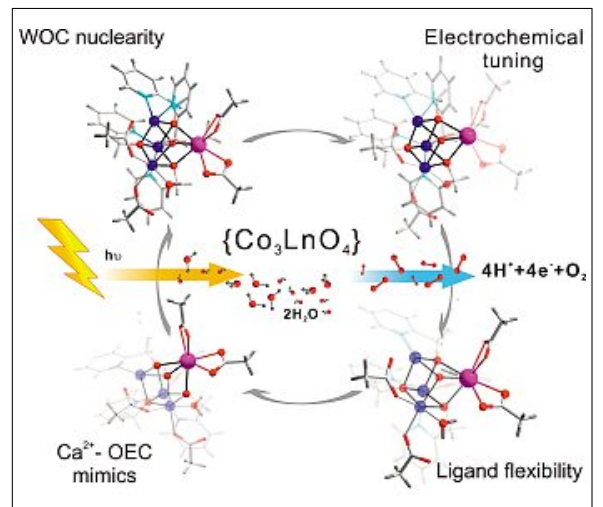
with molecular dynamics studies.

\section{Synthesis of Fijiolide A via an Atropselective Paracyclophane Formation}

C. Heinz and N. Cramer*, J. Am. Chem. Soc. 2015, 137, 11278. EPF Lausanne

Fijiolide A is a secondary metabolite isolated from a marinederived actinomycete displaying inhibitory activity against TNF- $\alpha$-induced activation of NFKB, an important transcription factor and a potential target for the treatment of different cancers and inflammation related diseases. Fijiolide A is a glycosylated complex paracyclophane, which is structurally closely related to the Bergman-aromatization product of enediyne C-1027. Cramer and Heinz report an enantioselective synthesis of fijiolide A demonstrating the power of fully intermolecular rutheniumcatalysed $[2+2+2]$-cyclotrimerizations with three different alkynes to assemble the heavily substituted central arene core. The characteristic strained [2.6]-paracyclophane structure is accessed by a templated atropselective macroetherification reaction.

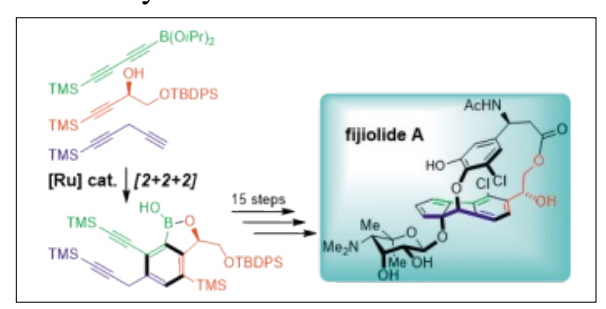

Prepared by Caroline D. Bösch, Markus Probst, Yuliia Vyborna, Mykhailo Vybornyi, Simon M. Langenegger and Robert Häner* Do you want your article to appear in the SWISS SCIENCE CONCENTRATES highlight?

Please contact robert.haener@dcb.unibe.ch 